\title{
High performance liquid chromatography for simultaneous determination of xipamide, triamterene and hydrochlorothiazide in bulk drug samples and dosage forms
}

\author{
SOAD S. ABD EL-HAY ${ }^{1,2}$ \\ HISHAM HASHEM ${ }^{2,3}$ \\ AYMAN A. GOUDA ${ }^{4}$ \\ ${ }^{1}$ Faculty of Pharmacy \\ Pharmaceutical Chemistry Department \\ King Abdulaziz University \\ Saudi Arabia \\ ${ }^{2}$ Faculty of Pharmacy \\ Department of Analytical Chemistry \\ Zagazig University, Egypt \\ ${ }^{3}$ Faculty of Pharmacy \\ Pharmaceutical Chemistry Department \\ Jazan University, Saudi Arabia \\ ${ }^{4}$ Faculty of Science \\ Department of Analytical Chemistry \\ Zagazig University, Egypt
}

Accepted December 18, 2015

Online published February 8, 2016

\begin{abstract}
A novel, simple and robust high-performance liquid chromatography (HPLC) method was developed and validated for simultaneous determination of xipamide (XIP), triamterene (TRI) and hydrochlorothiazide (HCT) in their bulk powders and dosage forms. Chromatographic separation was carried out in less than two minutes. The separation was performed on a RP C-18 stationary phase with an isocratic elution system consisting of $0.03 \mathrm{~mol} \mathrm{~L}{ }^{-1}$ orthophosphoric acid ( $\mathrm{pH} 2.3$ ) and acetonitrile ( $\mathrm{ACN}$ ) as the mobile phase in the ratio of 50:50, at $2.0 \mathrm{~mL} \mathrm{~min}^{-1}$ flow rate at room temperature. Detection was performed at $220 \mathrm{~nm}$. Validation was performed concerning system suitability, limits of detection and quantitation, accuracy, precision, linearity and robustness. Calibration curves were rectilinear over the range of $0.195-100 \mu \mathrm{g} \mathrm{mL} \mathrm{m}^{-1}$ for all the drugs studied. Recovery values were $99.9,99.6$ and $99.0 \%$ for XIP, TRI and HCT, respectively. The method was applied to simultaneous determination of the studied analytes in their pharmaceutical dosage forms.
\end{abstract}

Keywords: xipamide, triamterene, hydrochlorothiazide, HPLC, simultaneous analysis

Xipamide (XIP, 4-chloro-2,6-dimethyl-5-sulfamoylsalicylanilide) (1) is used for high blood pressure and edema control with a moderately powerful diuretic action (2). Several procedures have been developed for its determination, which include spectrophotometry (3-5), spectrofluorimetry (5,6), TLC-densitometry (4) and HPLC (7-12).

Triamterene (TRI, 6-phenyl-2,4,7-triaminopteridine) (1) is a relatively inefficient antihypertensive when used alone; hence it is used in combination with some potent diuretic (e.g., anthranilic acid or thiazide derivative) to give a synergistic action (13). Literature survey reveals that TRI has been determined by spectrophotometric $(4,14-18)$, fluorimetric $(19,20)$ and chromatographic $(7,21,22)$ methods.

\footnotetext{
*Correspondence; e-mail: sabdulhai@kau.edu.sa
} 
Hydrochlorothiazide (HCT, 6-chloro-3,4-dihydro-2H-1,2,4- benzothiadiazine-7-sulphonamide-1,1-dioxide) (1) is used as an effective diuretic and antihypertensive agent. Previous methods described for HCT determination include spectrophotometry $(15-17,23)$, HPTLC with fluorimetric detection (23) and $\operatorname{HPLC}(17,21,24-26)$.

Literature review revealed that a few methods were developed for determination of XIP and TRI together $(4,7)$ or TRI with $\operatorname{HCT}(15-17,21)$; however, these methods suffer either from low sensitivity or long separation time. In addition, the single-pill, triple-combination antihypertensive therapy has been widely accepted as an effective, well-tolerated, and convenient strategy that can help hypertensive patients (27). Nevertheless, nowadays there is no one dosage form that includes the three drugs analyzed in this study all together. Therefore, the development of a simple, reproducible and sensitive HPLC method for their simultaneous determination in a mixture of bulk drug samples or in a combined dosage form would be very important.

Chemical structures of all three analytes are given in Fig. 1.

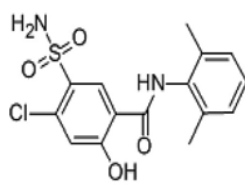

Xipamide<smiles>Nc1nc(N)c2nc(-c3ccccc3)c(N)nc2n1</smiles>

Triamterene<smiles>NS(=O)(=O)c1cc2c(cc1Cl)NCNS2(=O)=O</smiles>

Hydrochlorothiazide

Fig. 1. Chemical structures of the analytes.

\section{EXPERIMENTAL}

\section{Materials and reagents}

Analytical HPLC grade solvents were used in all experiments, including methanol and ACN (POCH S.A., Poland). Orthophosphoric acid $85 \%$ and sodium hydroxide (Burdick \& Jackson, USA) were used. Double distilled water was used. Xipamide (99.09\%), triamterene (99.91 \%) and hydrochlorothiazide (99.50 \%) were kindly supplied by EIPICO Pharmaceutical Industries Company, Egypt. The pharmaceutical dosage forms used were Epitens $^{\circledR}$ (Egyptian International Pharmaceutical Industry Co, Egypt, $30 \mathrm{mg}$ TRI and $10 \mathrm{mg}$ XIP per tablet) and Moduretic ${ }^{\circledR}$ (Kahira Company for Pharmaceuticals, Egypt, 50 mg HCT and $5 \mathrm{mg}$ amiloride per tablet). There is no formulation in the Egyptian market that includes HCT only. This is why Moduretic ${ }^{\circledR}$, containing HCT and amiloride, was analyzed for HCT contents.

\section{Chromatographic conditions}

HPLC apparatus (Agilent 1100, Agilent, USA) composed of a quaternary pump G1310A with quaternary solvent cabinet, vacuum degasser G1322A and a four-channel gradient pump, autosampler G1313A, variable wavelength detector G1314A with standard 10-mm pathlength-flow cell (14 $\mu \mathrm{L}$ volume, $4 \times 10^{6} \mathrm{~Pa}$ maximum pressure). Separations were performed on an Agilent 5- $\mu$ m Hypersil BDS C18 column (150 x 4.6 mm i.d.). A pH meter Jenway 4330 (Jenway, UK) was used. 


\section{Validation}

For the determination of XIP, TRI and HCT, an isocratic mobile phase consisting of ACN : $0.03 \mathrm{~mol} \mathrm{~L}^{-1} \mathrm{H}_{3} \mathrm{PO}_{4}(\mathrm{pH} 2.3)(50: 50, \mathrm{~V} / \mathrm{V})$ at a flow rate of $2.0 \mathrm{~mL} \mathrm{~min}{ }^{-1}$ was applied. $\mathrm{pH}$ readings always belong to the aqueous part of the mobile phase. For each run, $10 \mu \mathrm{L}$ of sample was injected. Detection was achieved at $220 \mathrm{~nm}$.

The proposed analytical method was validated through linearity, limits of detection and quantitation, accuracy, precision and robustness according to the guidelines (28-30). The limits of detection $(L O D)$ and quantification $(L O Q)(29,30)$ were defined as the injected quantities giving a signal-to-noise of 3 and 10, respectively, in terms of peak height (Table I).

To obtain calibration graphs, drug concentrations in the range of $0.195-100 \mu \mathrm{g} \mathrm{mL} \mathrm{L}^{-1}$ were used. Peak areas were plotted against the corresponding injected concentrations.

Checking of chromatographic parameters was done using the standard mixture solution. They include retention time, resolution $\left(R_{\mathrm{s}}\right)$, selectivity factor $(\alpha)$, symmetry and $N$ (theoretical plates) (Table I).

Table I. Chromatographic, linear regression and limiting data for the determination of XIP, TRI, and HCT using the proposed HPLC method

\begin{tabular}{lccc}
\hline Parameter & Xipamide & Triamterene & Hydrochlorothiazide \\
\hline Chromatographic parameters & & & \\
$t_{\mathrm{R}} \pm \mathrm{SD}(\mathrm{min})$ & $1.853 \pm 0.002$ & $1.493 \pm 0.002$ & $0.961 \pm 0.001$ \\
Resolution $\left(R_{\mathrm{s}}\right)$ & 3.17 & 4.50 & - \\
Selectivity $(\alpha)$ & 1.415 & 2.575 & - \\
Symmetry & 0.860 & 0.630 & 0.680 \\
$k^{\prime}$ & 1.973 & 1.397 & 0.54 \\
$N(150 \mathrm{~mm}$ column$)$ & 5607 & 2197.5 & 1252.75 \\
Linearity and regression data & & & \\
Linearity range $\left(\mu \mathrm{g} \mathrm{mL}^{-1}\right)$ & $0.195-100$ & $0.195-100$ & $0.195-100$ \\
$L O D\left(\mu \mathrm{g} \mathrm{mL}^{-1}\right)$ & 0.012 & 0.024 & 0.012 \\
$L O Q\left(\mu \mathrm{g} \mathrm{mL}^{-1}\right)$ & 0.04 & 0.08 & 0.04 \\
Slope $\pm \mathrm{RSD}^{\mathrm{a}}$ & $47.518 \pm 0.01$ & $40.429 \pm 0.02$ & $32.806 \pm 0.03$ \\
Intercept $\pm \mathrm{RSD}^{\mathrm{a}}$ & $0.4696 \pm 1.6$ & $3.8595 \pm 1.3$ & $2.3953 \pm 2.5$ \\
Coefficient of determination $\left(R^{2}\right)$ & 0.9999 & 0.9999 & 0.9999 \\
\hline
\end{tabular}

${ }^{\mathrm{a}} \mathrm{RSD}(\%)$

The precision study was performed by injection of the standard solution at four concentrations four times during a day or every day for four days in case of intra-day and inter-day precision, respectively (Table II). 
S. S. Abd El-Hay et al:: High performance liquid chromatography method for simultaneous determination of xipamide, triamterene and hydrochlorothiazide in bulk drug samples and dosage forms, Acta Pharm. 66 (2016) 109-118.

Table II. Intra- and inter-day precision determination of XIP, TRI and HCT using the proposed HPLC method

\begin{tabular}{|c|c|c|c|c|c|}
\hline \multirow[b]{2}{*}{ Drug } & \multicolumn{3}{|c|}{ Intra-day } & \multicolumn{2}{|c|}{ Inter-day } \\
\hline & $\begin{array}{l}\text { Added conc. } \\
\left(\mu \mathrm{g} \mathrm{mL} \mathrm{L}^{-1}\right)\end{array}$ & $\begin{array}{c}\text { Recovery } \\
(\%)^{\mathrm{a}}\end{array}$ & $\begin{array}{l}\text { RSD } \\
(\%)\end{array}$ & $\begin{array}{c}\text { Recovery } \\
(\%)^{\mathrm{a}}\end{array}$ & $\begin{array}{l}\text { RSD } \\
(\%)\end{array}$ \\
\hline \multirow{4}{*}{ Xipamide } & 12.50 & 96.8 & 0.1 & 99.7 & 1.5 \\
\hline & 25.00 & 97.6 & 0.1 & 98.8 & 1.1 \\
\hline & 50.00 & 99.4 & 0.4 & 99.7 & 0.2 \\
\hline & 100.00 & 101.5 & 0.1 & 101.3 & 1.0 \\
\hline \multirow{4}{*}{ Triamterene } & 12.50 & 98.8 & 0.7 & 97.3 & 1.9 \\
\hline & 25.00 & 98.9 & 0.3 & 97.3 & 1.4 \\
\hline & 50.00 & 99.3 & 0.4 & 98.4 & 0.8 \\
\hline & 100.00 & 101.1 & 0.4 & 100.2 & 0.8 \\
\hline \multirow{4}{*}{$\begin{array}{l}\text { Hydrochloro- } \\
\text { thiazide }\end{array}$} & 12.50 & 99.7 & 0.7 & 99.9 & 1.8 \\
\hline & 25.00 & 99.4 & 0.5 & 98.1 & 1.3 \\
\hline & 50.00 & 99.1 & 0.2 & 99.3 & 0.3 \\
\hline & 100.00 & 100.7 & 0.2 & 100.9 & 0.5 \\
\hline
\end{tabular}

${ }^{a}$ Recovery of the label claim. Mean of four determinations.

Stability of the standard solution was checked through injection of the prepared solution at intervals into the chromatograph for up to about 7 days.

Robustness of the method was studied for small changes in the flow rate $( \pm 0.1 \mathrm{~mL}$ $\left.\min ^{-1}\right), \%$ of $\mathrm{ACN}( \pm 0.5 \%)$, wavelength of detection $( \pm 1 \mathrm{~nm})$ and injection volume $( \pm 0.5$ $\mu \mathrm{L})$.

\section{Preparation of standard solutions}

Ten mg of XIP, TRI and HCT were dissolved in $10 \mathrm{~mL}$ methanol and then completed to $100 \mathrm{~mL}$ with $\mathrm{H}_{2} \mathrm{O}$ to give the stock solution $\left(0.1 \mathrm{mg} \mathrm{mL}^{-1}\right)$. Working standard solutions were prepared by diluting aliquots of stock solutions with the same diluting solvent $(10 \%$ methanol in water) to obtain concentrations ranging from $0.195-100 \mu \mathrm{g} \mathrm{mL}^{-1}$ for all the studied drugs.

\section{Assay of tablets}

Ten tablets of Epitens ${ }^{\circledR}$ and Moduretic ${ }^{\circledR}$ were finely powdered, separately. An accurately weighed quantity of the powders equivalent to $30 \mathrm{mg}$ TRI and $10 \mathrm{mg}$ XIP in case of Epitens ${ }^{\circledR}$ and equivalent to $50 \mathrm{mg}$ HCT in case of Moduretic ${ }^{\circledR}$ tablets were transferred into $100-\mathrm{mL}$ volumetric flasks and extracted using $10 \mathrm{~mL}$ methanol and then completed to 100 $\mathrm{mL}$ with water. The flasks were shaken for $15 \mathrm{~min}$ using an ultrasonic shaker and then filtered into dry conical flasks. Aliquots of the filtrates $(25$ and $10 \mathrm{~mL})$ of Epitens ${ }^{\circledR}$ and Moduretic ${ }^{\circledR}$, respectively, were separately transferred into $100-\mathrm{mL}$ volumetric flasks and diluted to volumes with the diluting solvent to prepare solutions containing $25 \mu \mathrm{g} \mathrm{mL} \mathrm{L}^{-1} \mathrm{XIP}$, 
$75 \mu \mathrm{g} \mathrm{mL}{ }^{-1}$ TRI in case of Epitens ${ }^{\circledR}$ tablets and $50 \mu \mathrm{g} \mathrm{mL}^{-1}$ HCT in case of Moduretic ${ }^{\circledR}$ tablets.

Epitens ${ }^{\circledR}$ tablets extract (XIP and TRI) and Moduretic ${ }^{\circledR}$ tablets extract (HCT) were determined separately.

Also, a laboratory prepared mixture composed of tablet solutions of XIP and TRI (Epitens ${ }^{\circledR}$ ) and HCT $\left(\right.$ Moduretic ${ }^{\circledR}$ ) was prepared and then analyzed.

\section{RESULTS AND DISCUSSION}

\section{Method optimization}

Optimization of different experimental conditions was carried out at the detection wavelength of $220 \mathrm{~nm}$, which gives the best sensitivity for all three analytes.

Elution of TRI, XIP and HCT was achieved at reasonable retention times (2 minutes) using $50 \% \mathrm{ACN}$ in the mobile phase (Fig. 2). Longer retention times were obtained at lower concentrations of ACN, while increasing the ACN concentration to $60 \%$ led to overlap of XIP with TRI peaks (eluted together at $1.571 \mathrm{~min}$ ). $\mathrm{pH} 2.3$ of the aqueous part of the mobile phase was chosen as the optimum $\mathrm{pH}$ providing the best peak symmetry and sharpness adding to reasonable separation, retention times and peak shape.

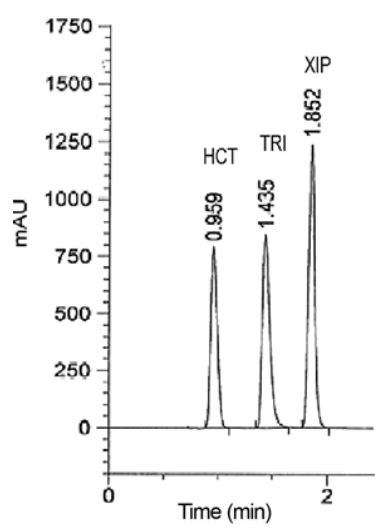

Fig. 2. Typical chromatogram of a $10-\mu \mathrm{L}$ injection of a standard mixture of $100 \mu \mathrm{g} \mathrm{mL} \mathrm{L}^{-1} \mathrm{XIP}$, TRI and HCT using $0.03 \mathrm{~mol} \mathrm{~L}^{-1}$ orthophosphoric acid (pH 2.3) and ACN (50:50) as the mobile phase at a flow rate of $2.0 \mathrm{~mL} \mathrm{~min}^{-1}$ and detection at $220 \mathrm{~nm}$.

\section{Validation}

Linearity and limiting values. - The results indicate that there is a wide linearity range (0.195-100 $\mu \mathrm{g} \mathrm{mL}^{-1}$ with $\left.R^{2}>0.999\right)$ as well as low LOD $\left(0.01-0.02 \mu \mathrm{g} \mathrm{mL}^{-1}\right)$ and LOQ (0.04$0.08 \mu \mathrm{g} \mathrm{mL}^{-1}$ ) values. Resolution is greater than 1.5 and symmetry factors for all analytes are $0.6-0.9$ (see Table I). 
Selectivity and specificity of the method. - The presence of amiloride co-formulated with HCT did not affect separation and quantitation of HCT. We assume that the peak at $1.3 \mathrm{~min}$ may be ascribed to amiloride. We can also conclude that there was no interference of other additives in the formulations (Fig. 3). Detection and validated quantitation of amiloride is our next task.
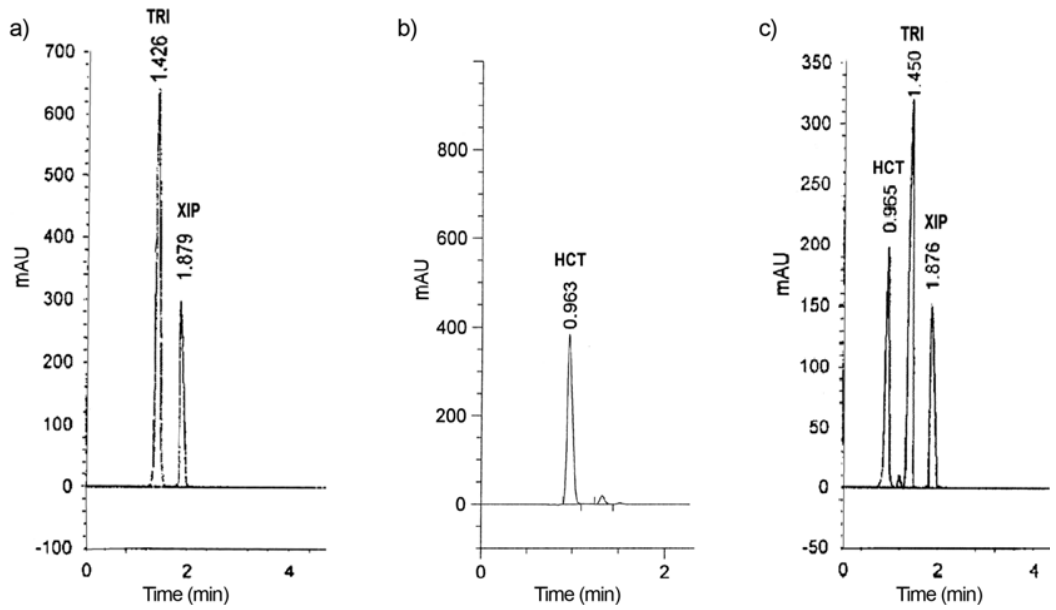

Fig. 3. Application of the proposed HPLC method for the determination of:a) XIP, TRI in Epitens ${ }^{\circledR}$ tablets, b) HCT in Moduretic ${ }^{\circledR}$ tablets, c) laboratory prepared mixture of the tablet solutions (XIP and TRI from Epitens ${ }^{\circledR}$, HCT from Moduretic ${ }^{\circledR}$, under optimized chromatographic conditions.

Precision. - Good intra- and inter-day precision was indicated by RSD values of $0.1-0.7$ and $0.2-1.9 \%$, resp. (Table II).

Stability and robustness. - The results of stability tests reveal that the RSD of the peak area was within $1.0 \%$. The results of robustness studies indicated that the method is much more sensitive to slight variations in the flow rate (Figs. $4 a$ and b) and \% of ACN (Figs. 4c and d) with RSD values within $3.9 \%$. The decrease in ACN percentage led to an increase of retention times for all the studied drugs. Small changes in the wavelength of detection and injection volume had no significant effect on the peak area and retention time for all the studied drugs (RSD values lower than $1.0 \%$, Table III).

\section{Accuracy of the new method and application for analysis of XIP, TRI and HCT in tablets}

Laboratory prepared mixture (containing all analytes) was composed of Epitens ${ }^{\circledR}$ and Moduretic ${ }^{\circledR}$ tablet solutions. The analysis has shown good accuracy with good recoveries of the label claim (mean \pm RSD, $n=3$ ) $98.9 \pm 1.1$, $97.8 \pm 1.4$ and $99.1 \pm 1.5 \%$ for XIP, TRI and HCT, respectively (Table IV). For all three analytes, the model accuracy obtained from standard solutions within the linearity range covers the interval of 97 to $102 \%$ (Table II). 

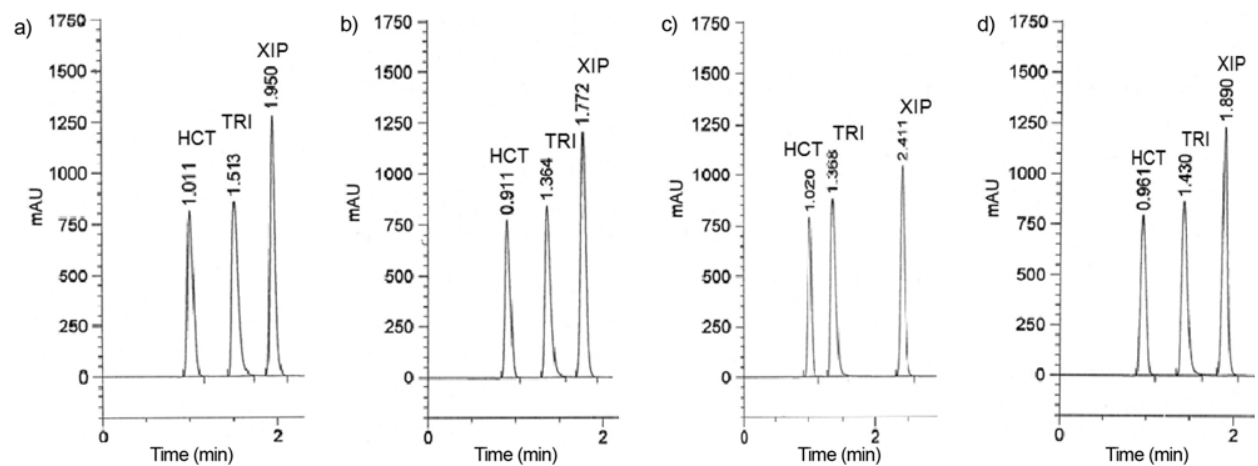

Fig. 4. Robustness of the proposed HPLC method from a typical chromatogram of a 10- $\mu \mathrm{L}$ injection of a standard mixture of $100 \mu \mathrm{g} \mathrm{mL}^{-1}$ XIP, TRI and HCT: a) flow rate $1.9 \mathrm{~mL} \mathrm{~min}{ }^{-1}$, b) flow rate $2.1 \mathrm{~mL}$ $\min ^{-1}$, c) $49.5 \% \mathrm{ACN}$, d) $50.5 \% \mathrm{ACN}$. Other conditions are as optimized.

Table III. Robustness of the proposed HPLC method

\begin{tabular}{|c|c|c|c|c|c|c|c|}
\hline \multirow{2}{*}{\multicolumn{2}{|c|}{$\begin{array}{c}\text { Analyte } \\
\text { concentration } \\
\left(\mu \mathrm{g} \mathrm{mL} \mathrm{m}^{-1}\right)\end{array}$}} & \multicolumn{2}{|c|}{$\begin{array}{c}\text { Injection volume } \\
(\mu \mathrm{L})\end{array}$} & \multicolumn{2}{|c|}{$\begin{array}{l}\text { Detection wavelength } \\
(\mathrm{nm})\end{array}$} & \multicolumn{2}{|c|}{$\begin{array}{l}\text { Flow rate } \\
\left(\mathrm{mL} \mathrm{min}^{-1}\right)\end{array}$} \\
\hline & & 9.5 & 10.5 & 219 & 221 & 1.9 & 2.1 \\
\hline \multirow{2}{*}{$\hat{\bar{x}}$} & 50 & 0.2 & 0.0 & 0.1 & 0.0 & 3.4 & 3.4 \\
\hline & 100 & 0.0 & 0.2 & 0.1 & 0.9 & 3.7 & 3.1 \\
\hline \multirow{2}{*}{$\underset{\sim}{\vec{q}}$} & 50 & 0.1 & 0.1 & 0.0 & 0.1 & 3.6 & 3.9 \\
\hline & 100 & 0.1 & 0.0 & 0.1 & 0.1 & 3.6 & 3.7 \\
\hline \multirow{2}{*}{ 㫐} & 50 & 0.3 & 0.1 & 0.3 & 0.2 & 3.6 & 3.9 \\
\hline & 100 & 0.1 & 0.1 & 0.1 & 0.4 & 3.7 & 3.7 \\
\hline
\end{tabular}

Table IV. Application of the proposed HPLC method for simultaneous determination of XIP, TRI and HCT in a laboratory prepared mixture of Epitens ${ }^{\circledR}$ and Moduretic ${ }^{\circledR}$ tablets $^{a}$

\begin{tabular}{|c|c|c|c|c|c|}
\hline \multicolumn{2}{|c|}{ XIP } & \multicolumn{2}{|c|}{ TRI } & \multicolumn{2}{|c|}{ HCT } \\
\hline $\begin{array}{l}\text { Taken conc. } \\
\left(\mu \mathrm{g} \mathrm{mL} L^{-1}\right)\end{array}$ & $\begin{array}{c}\text { Recovery } \\
(\%)\end{array}$ & $\begin{array}{l}\text { Taken conc. } \\
\left(\mu \mathrm{gL}^{-1}\right)\end{array}$ & $\begin{array}{l}\text { Recovery } \\
\text { (\%) }\end{array}$ & $\begin{array}{l}\text { Taken conc. } \\
\left(\mu \mathrm{g} \mathrm{mL}^{-1}\right)\end{array}$ & $\begin{array}{c}\text { Recovery } \\
\text { (\%) }\end{array}$ \\
\hline 8.33 & 99.8 & 25.00 & 96.8 & 16.66 & 98.1 \\
\hline 12.50 & 98.2 & 37.50 & 98.7 & 25.00 & 100.2 \\
\hline Mean $^{a}$ & 98.9 & & 97.8 & & 99.1 \\
\hline RSD (\%) & 1.2 & & 1.4 & & 1.5 \\
\hline
\end{tabular}

a Average of four experiments. 
When the results of the method for determination of the three analytes were statistically compared with those obtained from the reported HPLC methods $(7,24)$, it was found that there was no significant difference between them regarding accuracy and precision, since the calculated $t$ - and $F$-values were lower than the corresponding tabulated ones (Table V).

Table V. Determination of XIP, TRI and HCT by the proposed HPLC method compared to reported methods

\begin{tabular}{llcc}
\hline Drug & & This paper & Reported methods \\
\hline \multirow{4}{*}{ Xipamide } & Mean (\%) & 99.9 & 98.3 (ref. 7) \\
& RSD (\%) & 1.9 & 1.4 \\
& Student's $t$-test & $1.53(1.83)^{\mathrm{a}}$ & - \\
& F-test & $1.77(5.19)^{\mathrm{a}}$ & - \\
& $n$ & 6 & 5 \\
\hline \multirow{3}{*}{ Triamterene } & Mean (\%) & 99.6 & 100.4 (ref. 7) \\
& RSD (\%) & 0.7 & 0.9 \\
& Student's $t$-test & $1.6(1.86)^{\mathrm{a}}$ & - \\
& F-test & $1.61(6.39)^{\mathrm{a}}$ & - \\
& $n$ & 5 & 5 \\
\hline \multirow{3}{*}{ Hydrochlorothiazide } & Mean (\%) & 99.4 & 0.5 \\
& RSD (\%) & 1.0 & - \\
& Student's $t$-test & $0.54(1.83)^{\mathrm{a}}$ & - \\
& $F$-test & $4.16(5.19)^{\mathrm{a}}$ & 6 \\
\hline
\end{tabular}

a The figures in parentheses are the theoretical values for $t$ - and $F$-tests $(p<0.05)$.

\section{CONCLUSIONS}

A simple, fast and specific HPLC method has been described for simultaneous determination of xipamide, triamterene and hydrochlorothiazide in their pure form and in pharmaceutical preparations. The proposed method is of great interest for routine sample analysis and quality control of the analyzed drugs because of the short chromatographic run time (2 minutes) allowing a large sample throughput. When compared to the previously reported methods, the new method is simple, cost effective, precise, sensitive and accurate.

\section{REFERENCES}

1. The Merck Index, An Encyclopedia of Chemicals, Drugs and Biologicals, $14^{\text {th }}$ ed. (M. J. O'Neil, Ed.) Merck, John Wiley and Sons, Whitehouse Station/Rahway, 2006.

2. Martindale, The Complete Drug Reference, $36^{\text {th }}$ ed., S. Sweetman, Ed., Pharmaceutical Press Mondin, 2009. 
3. N. M. El Guindi, S. M. Abd-Elhamid, W. M. M. El-Bakry and M. F. El-Shahat, Quantitative determination of xipamide in pure form and in tablets through complexation with iron(III) chloride, J. Drug Res. 31 (2010) 93-99.

4. N. E. Wagieh, S. S. Abbas, M. Abdelkawy and M. M. Abdelrahman, Spectrophotometric and spectrodensitometric determination of triamterene and xipamide in pure form and in pharmaceutical formulation, Drug Test Anal. 2 (2010) 113-121; DOI: 10.1002/dta.92.

5. M. A. Omar, Spectrophotometric and spectrofluorimetric determination of certain diuretics through ternary complex formation with eosin and lead (II), J. Fluoresc. 20 (2010) 275-281; DOI: 10.1007/s10895-009-0551-2.

6. M. I. Walash, N. El-Enany, M. I. Eid and M. E. Fathy, Stability-indicating spectrofluorimetric methods for the determination of metolazone and xipamide in their tablets. Application to content uniformity testing, J. Fluoresc. 24 (2014) 363-376; DOI 10.1007/s10895-013-1301-z.

7. H. M. Maher, R. M. Youssef, E. I. El-Kimary, E. M. Hassan and M. A. Barary, Bioavailability study of triamterene and xipamide using urinary pharmacokinetic data following single oral dose of each drug or their combination, J. Pharm. Biomed. Anal. 61 (2012) 78-85; DOI: 10.1016/j.jpba.2011. 11.032 .

8. M. J. Ruiz-Angel, J. R. Torres-Lapasio and M. C. Garcia-Alvarez-Coque, Effects of pH and the presence of micelles on the resolution of diuretics by reversed-phase liquid chromatography, J. Chromatogr. A 1022 (2004) 51-65; DOI: 10.1016/j.chroma.2003.09.061.

9. A. Rosado-Maria, A. I. Gasco-Lopez, A. Santos-Montes and R. Izquierdo-Hornillos, High-performance liquid chromatographic separation of a complex mixture of diuretics using a micellar mobile phase of sodium dodecyl sulfate. Application to human urine samples, J. Chromatogr. B 748 (2000) 415-424; DOI: 10.1016/S0378-4347(00)00367-4.

10. M. J. Legorburu, R. M. Alonso and R. M. Jimenez, Determination of the non-thiazide diuretic xipamide in pharmaceuticals and urine by HPLC with amperometric detection, J. Liq. Chromatogr. Relat. Technol. 22 (1999) 735-746; DOI: 10.1081/JLC-100101695.

11. E. Bonet-Domingo, J. R. Torres-Lapasio, M. J. Medina-Hernandez and M. C. Garcia-AlvarezCoque, Chromatographic monitoring of diuretics in urine samples using a sodium dodecyl sulfate-propanol micellar eluent, Anal. Chim. Acta 287 (1994) 201-210; DOI: 10.1016/0003-2670(93) E0598-2.

12. S. Bodenan, M. Paillet and M. O. Christen, Rapid determination of xipamide in human plasma and urine by high performance liquid chromatography, J. Chromatogr. B 533 (1990) 275-281; DOI: 10.1016/S0378-4347(00)82214-8.

13. Clarke's Analysis of Drugs and Poisons, $3^{\text {rd }}$ ed., A. C. Moffat, M. D. Osselton and B. Widdop, Eds., Pharmaceutical Press, London 2004.

14. A. S. Al-Kady and F. I. Abdelmonem, Highly sensitive and selective spectrophotometric detection of trace amounts of $\mathrm{Hg}^{2+}$ in environmental and biological samples based on 2,4,7-triamino-6phenylpteridine, Sensor. Actuat. B-Chem. 182 (2013) 87-94; DOI: 10.1016/j.snb.2013.02.102.

15. K. Mohammadpour, M. R. Sohrabi and A. Jourabchi, Continuous wavelet and derivative transform applied to the overlapping spectra for the quantitative spectrophotometric multi-resolution of triamterene and hydrochlorothiazide in triamterene-H tablets, Talanta 81 (2010) 1821-1825; DOI: 10.1016/j.talanta.2010.03.040.

16. M. Stolarczyk, A. Apola, J. Krzek and K. Lech, Simultaneous determination of triamterene and hydrochlorothiazide in tablets using derivative spectrophotometry, Acta Pol. Pharm. 65 (2008) 283-287.

17. A. Jończyk and Z. Nowakowska, Determination of hydrochlorothiazide, triamterene and propranolol hydrochloride by the spectrophotometric method and high-performance liquid chromatography (HPLC), Acta Pol. Pharm. 58 (2002) 339-344; Bhawar et al., Indian J. Pharm. Sci. 70 (2008) 529-531. 
18. I. D. Meras, A. E. Mansilla, F. S. Lopez and M. J. Rodriguez Gomez, Determination of triamterene and leucovorin in biological fluids by UV derivative spectrophotometry and partial least-squares (PLS-1) calibration, J. Pharm. Biomed. Anal. 27 (2002) 81-90; DOI: 10.1016/S0731-7085(01)00512-X.

19. G. A. Ibañez, G. M. Escandar, A. Espinosa Mansilla and A. Muñoz de la Peña, Determination of triamterene in pharmaceutical formulations and of triamterene and its main metabolite hydroxytriamterene sulfate in urine using solid-phase and aqueous solution luminescence, Anal. Chim. Acta. 538 (2005) 77-84; DOI: 10.1016/j.aca.2005.02.001.

20. M. L. Luis, J. M. G. Fraga, A. I. Jiménez, F. Jiménez, O. Hernández and J. J. Arias, Application of PLS regression to fluorimetric data for the determination of furosemide and triamterene in pharmaceutical preparations and triamterene in urine, Talanta 62 (2004) 307-316; DOI: 10.1016/j.talanta.2003.07.010.

21. H. Li, J. He, Q. Liu, Z. Huo, S. Liang and Y. Liang, Simultaneous analysis of hydrochlorothiazide, triamterene and reserpine in rat plasma by high performance liquid chromatography and tandem solid-phase extraction, J. Sep. Sci. 34 (2011) 542-547; DOI: 10.1002/jssc.201000754.

22. Z. Zhang, D. Wang, L. Zhang, M. Du and G. Chen, Determination of diuretics in human urine by hollow fiber-based liquid-liquid-liquid microextraction coupled to high performance liquid chromatography, Analyst 133 (2008) 1187-1194; DOI: 10.1039/b802679c.

23. B. Dhandapani and N. Thirumoorthy, Development and validation for the simultaneous quantification of nebivolol hydrochloride and hydrochlorothiazide by UV spectroscopy, RP-HPLC and HPTLC in tablets, E-J. Chem. 7 (2010) 341-348; DOI: 10.1155/2010/483495.

24. S. J. Joshi, P. A. Karbhari, S. I. Bhoir, K. S. Bindu and C. Das, RP-HPLC method for simultaneous estimation of bisoprolol fumarate and hydrochlorothiazide in tablet formulation, J. Pharm. Biomed. Anal. 52 (2010) 362-371; DOI: 10.1016/j.jpba.2009.10.021.

25. G. Feng, Z. Mengliang, C. Xiangyong, W. Zhonghua, S. Yantong and G. Jingkai, Simultaneous quantitation of hydrochlorothiazide and metoprolol in human plasma by liquid chromatographytandem mass spectrometry, J. Pharm. Biomed. Anal. 52 (2010) 149-154; DOI: 10.1016/j.jpba.2009. 12.012 .

26. S. Bhagwate and N. J. Gaikwad, Stability indicating HPLC method for the determination of hydrochlorothiazide in pharmaceutical dosage form, J. Appl. Pharm. Sci. 3 (2013) 88-92; DOI: 10.7324/ JAPS.2013.30215.

27. B. J. Epstein, N. K. Shah, and N. L. Borja-Hart, Management of hypertension with fixed-dose triple-combination treatments, Ther. Adv. Cardiovasc. Dis. 7 (2013) 246-259; DOI: 10.1177/17539447134 98638.

28. International Conference on Harmonization of Technical Requirements for Registration of Pharmaceuticals for Human Use, ICH Harmonized Tripartite Guideline, Validation of Analytical Procedures: Text and Methodology, Q2(R1), Dated 06 November 1996, ICH, London 2005.

29. United States Pharmacopeia 32, National Formulary 27, USP Convention, Rockville 2010.

30. J. N. Miller and J. C. Miller, Statistics and Chemometrics for Analytical Chemistry, $5^{\text {th }}$ ed., Pearson Education Limited, Harlow 2005. 